\title{
Physiological and behavioral responses to an electrical stimulus in Mozambique tilapia (Oreochromis mossambicus)
}

\author{
Jonathan A. C. Roques - Wout Abbink - Gaétan Chereau • \\ Aurélie Fourneyron - Tom Spanings • Dirk Burggraaf • \\ Ruud van de Bos $\cdot$ Hans van de Vis $\cdot$ Gert Flik
}

Received: 6 July 2011/Accepted: 5 December 2011/Published online: 24 December 2011

(C) The Author(s) 2011. This article is published with open access at Springerlink.com

\begin{abstract}
Consumer awareness of the need to improve fish welfare is increasing. Electrostunning is a clean and potentially efficient procedure more and more used to provoke loss of consciousness prior to killing or slaughtering (reviewed by Van de Vis et al. in Aquac Res 34:211-220, 2003). Little is known how (powerful) electrical stimuli, which do not stun immediately, are perceived by fish. We investigated responses of handheld Mozambique tilapia (Oreochromis mossambicus) to
\end{abstract}

Wageningen Aquaculture is a consortium of IMARES (Institute for Marine Resources \& Ecosystem Studies) and AFI (Aquaculture and Fisheries Group, Wageningen University), both part of Wageningen University \& Research Centre (WUR).

J. A. C. Roques - G. Chereau · A. Fourneyron ·

T. Spanings · G. Flik $(\bowtie)$

Department of Animal Physiology, Faculty of Science, Institute for Water and Wetland Research, Radboud University Nijmegen, Heyendaalseweg 135, Box 30, 6525 AJ Nijmegen, The Netherlands e-mail: g.flik@science.ru.nl

J. A. C. Roques - W. Abbink - D. Burggraaf .

H. van de Vis

Department of Aquaculture, IMARES Wageningen UR, Institute for Marine Resources and Ecosystem Studies, P.O. Box 77, 4400 AB Yerseke, The Netherlands

R. van de Bos

Department of Animals in Science and Society,

Division of Behavioural Neuroscience,

Faculty of Veterinary Medicine, Utrecht University,

PO Box 80.166, 3508 TD Utrecht, The Netherlands a standardized electric shock applied to the tailfin. The handling with the resulting unavoidable acute stress response was carefully controlled for. Fish responses were analyzed up to $24 \mathrm{~h}$ following the shock. Electric shock resulted in slightly higher levels in plasma cortisol, lactate, ionic levels, and osmolality, than handling alone. Plasma glucose had significantly increased $6 \mathrm{~h}$ after shock compared to handling, indicative of enhanced adrenergic activity. Mucus release from the gills, branchial $\mathrm{Na}^{+} / \mathrm{K}^{+}$ATPase activity, and chloride cell migration and proliferation, parameters that will change with strong adrenergic activation, were not affected. Decreased swimming activity and delay in resumption of chafing behavior indicated a stronger and differential response toward the electric shock. Responses to handling lasted shorter compared to those to an electric shock. The differential and stronger responses to the electric shock suggest that fish perceived the shock potentially as painful.

Keywords Mozambique tilapia $\cdot$ Nociception $\cdot$ Fish welfare $\cdot$ Tailfin electroshock $\cdot$ Behavior $\cdot$ Stress

\section{Introduction}

The international association for the study of pain (IASP) defines pain as an unpleasant sensory and emotional experience associated with actual or potential tissue damage, or described in terms of such damage (IASP 1979). The questions of pain, pain 
awareness, fear, and stress in fish are still subject of controversies. In humans, these processes depend on functions controlled and executed by the highly developed hippocampus, amygdala, and cerebral frontal lobes of the neocortex (Apkarian et al. 2005). The absence of identical/comparable structures in teleostean fish has led some researchers to conclude that fish cannot experience pain, fear, or stress (Bermond 1997; Rose 2002). Recently, homologies between the telencephalic medial pallium of the teleosts and the amygdala of mammals as well as between the teleostean lateral pallium and the mammalian hippocampus have been identified (Portavella et al. 2002). This suggests that parts of the fish telencephalon could function to interpret processes related to pain, pain awareness, and fear, as do their homologs in mammals. Differences in development and organization of fish brain, in particular the eversion of the telencephalon versus inversion in mammals, have contributed significantly to a late recognition of a neural substrate for fish cognitive abilities and assigning consciousness to fish, which is at the basis of pain and fear experiences in mammals.

Reviews by Braithwaite and Huntingford (2004) and Chandroo et al. (2004) present evidence that fish, despite their less developed telencephalon, have learning abilities at a level that implies cognitive abilities. For selected species (rainbow trout Oncorhynchus mykiss, Atlantic cod Gadus morhua, goldfish Carassius auratus, and Atlantic salmon Salmo salar, Nile tilapia Oreochromis niloticus), evidence has been advanced that fish do have the capacity to perceive painful stimuli and the adequate nociceptive fibers for the detection of potentially painful stimuli (Sneddon 2002; Nilsson et al. 2002; Nordgreen 2009); we have recently shown that tailfin clipping may be a painful experience in Nile tilapia and common carp (Roques et al. 2010). However, it should be emphasized that it is unlikely that fish, as well as animals in general, except maybe higher primates, have the capacity to experience suffering as humans do (Braithwaite and Huntingford 2004). Nociception, the detection of potentially harmful stimuli, is at the very basis of experiencing pain, that is, interpreting a nociceptive stimulus. Two types of nerve fibers are involved in the process of nociception: the myelinated A-fibers are involved in the transmission of well-localized acute pain, while unmyelinated C-fibers (simply isolated by glia) are involved in poorly localized unpleasant slow dull pain (Sneddon 2002; Pottinger and Pickering 1997; Lynn 1994). Sneddon (2002) identified these two types of fibers in the head the rainbow trout. More recently, Roques and coworkers identified these fibers in the tail of common carp Cyprinus carpio, where the stimulus of the current study was given (Roques et al. 2010).

A pain experience by definition involves both the nociceptive sensory machinery and the actual translation of harmful stimuli into a feeling of pain. Fish should possess then both a nociceptive system and cognitive capacities to experience pain in analogy to humans. Indeed, a limited, yet firm, literature supports that fish do detect harmful stimuli, respond to nociceptive stimuli but also may conceptualize pain (Braithwaite and Huntingford 2004; Chandroo et al. 2004; Sneddon 2002, 2003; Sneddon et al. 2003a, b; Roques et al. 2010). Nilsson et al. (2002) demonstrated explicit memory in Atlantic cod. Other examples of learning abilities include individual positioning in a social network, prey-predator relationship, avoidance of dangerous sites associated with negative experience and decision making based on outcomes of fights with conspecifics (Reviewed by Galhardo and Oliveira 2009). Therefore, it is reasonable to hypothesize that fish have a neural substrate for some form of consciousness and may also experience pain. As fish learn to avoid painful conditions, there must be a memory for such adverse events.

The aim of the present study was to assess the behavioral, physiological, and endocrine responses of Mozambique tilapia (Oreochromis mossambicus) to a presumed and standardized pain stimulus (electrical shock applied to the tail).

Swimming activity (number of crossings from dark to light sections of an aquarium) was monitored under the hypothesis that a stressor alters light/dark preference (Maximino et al. 2010). The delay of resuming the stereotypical chafing behavior was monitored following an electrical shock given to the tail fin; the handling associated with the shock treatment was controlled for. When chafing, fish shoot downward to the bottom, lay themselves on their flank, and chafe over the substrate, for up to ten times before rising again and resuming their previous position (Galhardo et al. 2008). Stressrelated plasma parameters together with parameters for osmoregulatory performance and branchial release of mucus were analyzed. This study was 
designed to discriminate the response to the application of an electric shock to the tailfin (a presumed painful stimulus), from handling stress.

Stress is a well-known confounder in pain research as the application of painful stimuli often goes with handling and induces a stress response that may obscure the response proper to, in this case, the electric shock. It may be difficult to distinguish between a stress response and a mild pain response as these responses are part of the fish's stress physiology. Therefore, we included for every group that received the electric shock a control for handling stress.

\section{Materials and methods}

Fish

Mozambique tilapia (O. mossambicus), weighing around $120 \mathrm{~g}$, were obtained from laboratory stock. Two weeks before the start of the experiment, fish were randomly divided into seven groups, housed in 140-1 aquaria with 10 fish each; the fish received pellet feed at $2 \%$ of the total body weight daily (Trouvit, Trouw, The Netherlands). The water quality was monitored for nitrogenous waste products daily $\left(\mathrm{NO}_{2}{ }^{-}<0.5 \mathrm{mg} / \mathrm{l}\right.$; $\left.\mathrm{NO}_{3}{ }^{-}<12.5 \mathrm{mg} / \mathrm{l} ; \mathrm{NH}_{4}{ }^{+}<0.5 \mathrm{mg} / \mathrm{l} ; \mathrm{O}_{2}>7.0 \mathrm{mg} / \mathrm{l}\right)$. Water $\mathrm{pH}$ (range: 7.3-7.7) and water temperature $\left(25 \pm 0.2^{\circ} \mathrm{C}\right)$ were continuously monitored; the light regime was $12 \mathrm{~h}$ light: $12 \mathrm{~h}$ dark. The study was approved by the Animal Experimental Committee at Lelystad, the Netherlands (Protocol: 2009143.c).

\section{Electrical shock}

Individual fish were caught by net and restrained in a $\mathrm{V}$-shaped box covered with a wet towel to immobilize it. The electrodes were placed at a caudoventral corner of the tailfin (Fig. 1). Chervova (1997) concluded that caudal fins are among the most sensitive zones for damage, due to aggressive behavior, in White Sea cod (Gadus morhua marisalbi) and steelhead salmon (Salmo mykiss). Fin damage is frequently observed in the wild as well as in aquaculture practices, with sorting and transport activities as major causes. Furthermore, A- $\delta$ and C-fibers, involved in nociception, were demonstrated in this fin area of common carp, C. carpio (Roques et al. 2010). Electricity (15 V $\mathrm{dc}, 64 \pm 34 \mathrm{~mA}$ ) was applied for $1 \mathrm{~s}$ to the tailfin, and

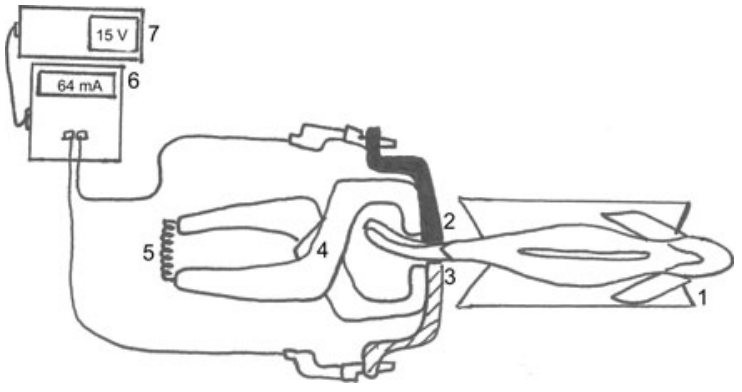

Fig. 1 Scheme of the electrical system used to provide the standardized electroshock. 1, V-shaped box covered with a wet towel to avoid desiccation. Fish were gently and manually restrained; 2 , anode; 3 , cathode; 4 , pliers; 5 , spring, adjusted to ensure standard stimulus; 6 , stimulator with digital indication of the current delivered; 7, electronic integrator with fixed value of voltage delivered (15 $\mathrm{V}$ per pulse)

subsequently the fish were immediately returned to their tank. Control for handling stress fish were handled the same way except that the electric shock was omitted (only the gentle pressure of the electrode application to the fin was given).

Seven groups of 10 fish were used (Table 1), including 1 (untreated) control group that was sampled for plasma analyses the day before the six experimental groups. Fish receiving an electric shock and controls were killed 1, 6 and $24 \mathrm{~h}$ after the shock or handling stress was given. Fish were not fed as of $24 \mathrm{~h}$ before sampling.

\section{Sampling}

The fish were quickly (within $20 \mathrm{~s}$ ) netted and deeply anaesthetized with 2-phenoxyethanol $(0.1 \% \mathrm{v} / \mathrm{v}$ in water; Sigma-Aldrich, St. Louis, USA); the fish lost equilibrium within $30 \mathrm{~s}$ and got deeply anaesthetized within $2 \mathrm{~min}$. Blood samples obtained by puncture of the caudal vessels with a heparinized syringe fitted with a 25 -gauge needle were immediately centrifuged at $4^{\circ} \mathrm{C}$ and $10,000 \times g$ for $10 \mathrm{~min}$ to separate plasma and cells; plasma was snap-frozen and stored at $-20^{\circ} \mathrm{C}$.

Two gill arches were excised and stored in SEI buffer $(150 \mathrm{mM}$ sucrose, $10 \mathrm{mM}$ EDTA, $50 \mathrm{mM}$ imidazole; $\mathrm{pH}$ : 7.4) for later determination of $\mathrm{Na}^{+} / \mathrm{K}^{+}$-ATPase enzymic activity or fixed in Bouin's (15 volumes saturated picric acid:5 volumes formaldehyde: 1 volume glacial acetic acid) for mucus cell and chloride cell (immuno-)histochemistry. 


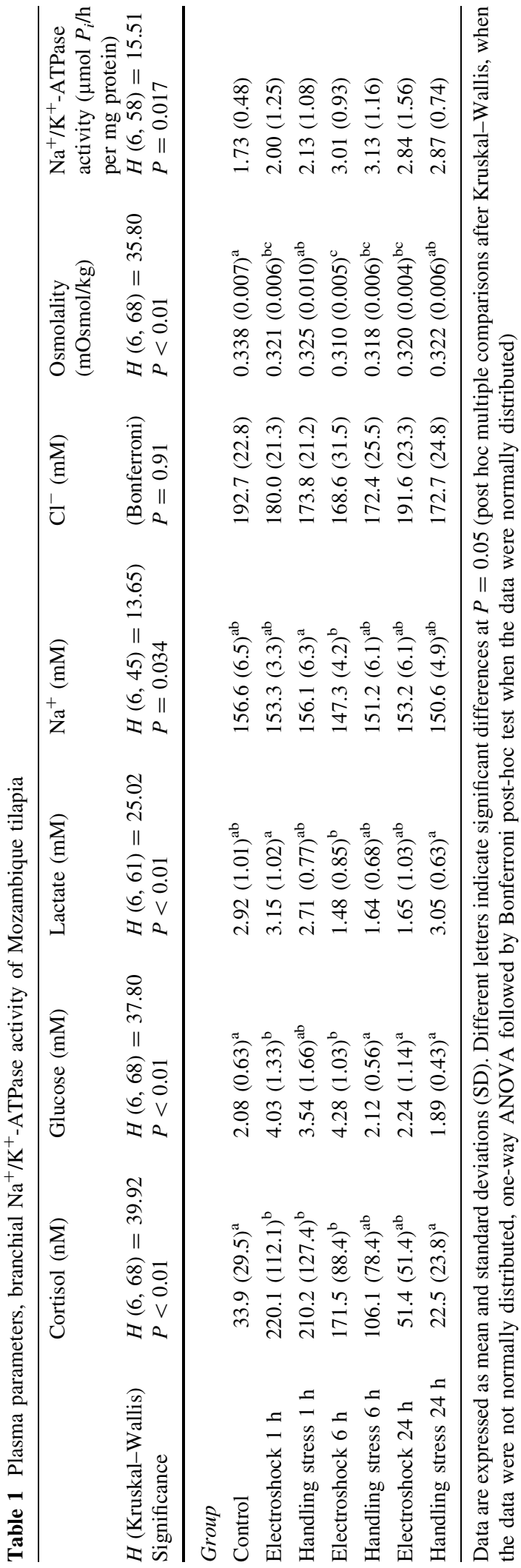

Behavior

Tanks were covered with black non-transparent plastic to make $50 \%$ of the volume of the tank dark and $50 \%$ illuminated. Behavior was recorded with a Samsung SHR-2040 4-Channel DVR Security System recorder linked with Sanyo's bullet video cameras. Activity was monitored continuously from $1 \mathrm{~h}$ prior stimulus to $6 \mathrm{~h}$ post stimulus, for $1.5 \mathrm{~h}$ prior the lights were switched off (9-10.5 h post stimulus) and for $1 \mathrm{~h}$ on the next morning ( $23 \mathrm{~h}$ post stimulus). The number of moves from one compartment to the other was registered. Transition from one to the other compartment was scored when the whole head of the animal crossed the border between the two compartments. Controls were analyzed similarly over a period of 5 days prior the stimulus application. Results are presented as averages of 4 periods of 15 min per hour.

We further investigated the delay to resume chafing behavior, which is prominent in tilapia. This may occur as a single act or in bouts of 10 or more within only a few seconds (Wyman and Walters-Wyman 1985).

\section{Blood plasma}

Plasma was analyzed for cortisol as described in detail before (Metz et al. 2005). Plasma glucose and lactate were measured with commercially available enzymatic test kits (Instruchemie, Delfzijl, The Netherlands), with protocols adapted to a 96-well microtiter plate. For glucose, $10 \mu \mathrm{l}$ sample or standard $(5.55 \mathrm{mM}$ glucose) was mixed with $200 \mu \mathrm{l}$ reagent and incubated for $10 \mathrm{~min}$ at $25^{\circ} \mathrm{C}$. Absorbance was read within $60 \mathrm{~min}$ at $495 \mathrm{~nm}$. For lactate, $10 \mu \mathrm{l}$ sample or standard (4.44 mM lactate) or blank (8\% perchloric acid) was mixed with $290 \mu \mathrm{l}$ of lactate reagent and incubated for $20 \mathrm{~min}$ at $37^{\circ} \mathrm{C}$. Absorbance was read at $355 \mathrm{~nm}$. Plasma osmolality (sample volumes: $50 \mu \mathrm{l}$ ) was measured with a cryoscopic osmometer (Osmomat 030, Gonotec, Germany). Deionized water $(0 \mathrm{mOsmol} / \mathrm{kg})$ and a standard solution $(300 \mathrm{mO}-$ $\mathrm{smol} / \mathrm{kg}$ ) were used as reference.

Gill histology

Gill samples fixed in Bouin's were dehydrated in a series of alcohols and embedded in paraffin. The samples were cut at $7 \mu \mathrm{m}$ and sections stained for the presence of mucus cells and chloride cells. Mucus was 
stained with Alcian blue. The mucus cell density was estimated by counting Alcian blue-positive cells in designated representative cross-sections stretching along 300 lamellae of the sampled gill arch (leading edge). Following noxious stimuli, mucus cells may expel their content resulting in a decreased frequency of Alcian blue-positive cells. Mucus cell frequency was assessed for each fish twice by the same person. Mucus cells are found in this species on both the leading and the trailing edge of the gill filament and were scored on both locations to avoid topological bias. Statistical analysis indicated that mucus cells are evenly distributed over the gill filament in this species $(P<0.05$; data not shown). Data from cell frequencies in the leading edge of the gill filaments are presented.

The chloride cells in the gills were detected through staining of their abundant $\mathrm{Na}^{+} / \mathrm{K}^{+}$-ATPase by immunohistochemistry with a monoclonal antibody raised against chicken $\mathrm{Na}^{+} / \mathrm{K}^{+}$-ATPase alpha-subunit (IgG $\alpha 5$, a generous gift of Dr. D. Farmbrough, Developmental Studies Hybridoma Bank, Department of Biological Sciences University of Iowa, USA). The $\mathrm{Na}^{+} / \mathrm{K}^{+}$-ATPase $\alpha-5$ antibody has been used in a number of studies to localize $\mathrm{Na}^{+} / \mathrm{K}^{+}$-ATPase in fish gills including in tilapia species (Dang et al. 2000; Metz et al. 2003). In tilapia, chloride cells predominate on the trailing edge of the filament (where the water flow exits the gill) and in the adjacent interlamellar space of the filamental epithelium (Van der Heijden et al. 1997). Sections of the trailing edge were scored for chloride cell incidence. Under stressful conditions, chloride cells may migrate from filamental to lamellar epithelium (Roques et al. 2010; Schram et al. 2010); we scored our samples for this migration. Enzymic activity of $\mathrm{Na}^{+} / \mathrm{K}^{+}$-ATPase activity as a measure of sodium pump capacity of the gills was determined by measuring the $\mathrm{K}^{+}$-dependent and ouabain-sensitive ATP-hydrolytic activity in a gill homogenate (Metz et al. 2003). As the bulk of the $\mathrm{Na}^{+} / \mathrm{K}^{+}$-ATPase is restricted to the chloride cells of the gills, a homogenate results in proper reflection of the sodium pump capacity of the chloride cell compartment.

\section{Statistics}

Physiological data are expressed as means plus or minus standard deviation (SD) (Table 1). When data were normally distributed (Kolgomorov-Smirnov test) and equality of variances verified (Levene's test), differences between groups were analyzed using oneway ANOVA followed by Bonferroni's post hoc test. When the conditions of validity were not met, the nonparametric Kruskal-Wallis ANOVA followed by the multiple comparison Wilcoxon rank-sum test was used to assess statistical significance of differences. Even mucus distribution over the gill filament was tests with a $t$ test for paired samples. Statistical differences for behavior data were assessed by the non-parametric Mann-Whitney $U$ test.

\section{Results}

Swimming activity

In control situations, the fish were very active in the early morning (7:00 until 11:00). Then activity declined gradually from 11:00 until the middle of the afternoon (16:00). There is an apparent revival in activity in the last one and a half hour prior to lights off (i.e., from 18:00 to 19:30). For both the handled-only group and the shocked group, there is a significant decrease in activity during the first $2 \mathrm{~h}$ post stimulus. Three hours post stimulus, the activity is still significantly lower for the group that received the electrical stimulus. Recovery seems to occur after $4 \mathrm{~h}$ in this group, while it is achieved after $3 \mathrm{~h}$ for the handlingonly group (Fig. 2a, b).

\section{Chafing behavior}

In controls, chafing was seen for all fish from 8:00 until 13:00, regardless of the sex or social status of the individuals. From 13:00 to 16:00, the incidence of this behavior declined, and it was mainly performed by dominant individuals. Performance incidence of this behavior gradual increased from 16:00 until lights were off (19:30). Both shocked and handled groups totally stopped displaying chafing behavior after the stimulus or the handling. The delay to resume chafing was $1 \mathrm{~h} 55 \mathrm{~min}$ for the handled-only group and $2 \mathrm{~h}$ $10 \mathrm{~min}$ (15 min later) for the group receiving the electroshock.

Stress and plasma analyses

Data on plasma concentrations of cortisol $(H(6, N=68)$ $=39.92, P<0.01)$ and glucose $(H(6, N=68)=37.80$, 


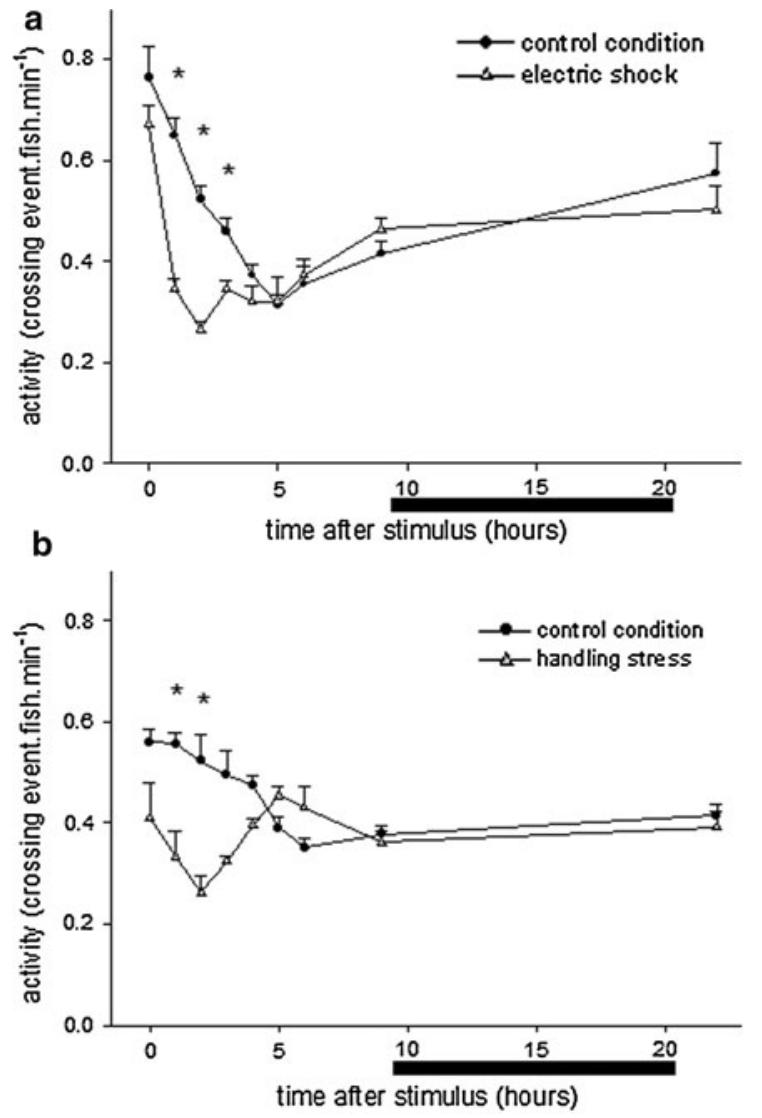

Fig. 2 Quantification of the general swimming (crossing) activity in Mozambique tilapia following several treatments; a electric shock versus its control; b handling stress versus its control situation; analysis for a period of $24 \mathrm{~h}$. Data are presented in number of crossing events per fish and per minute per periods of $1 \mathrm{~h}$ (10 fish per tank). Controls were analyzed similarly over a period of 5 days prior to the stimulus application. Results are presented as averages of 4 periods of 15 min per hour, and SEM. Tanks are divided into two distinct zones (covered vs. uncovered). Fish were considered to cross when their entire head was in the other compartment

$P<0.01$ ) (Table 1) showed the predicted changes resulting from stress. No significant differences between a shock and handling-only stress at $1 \mathrm{~h}$ after manipulation were observed. After $6 \mathrm{~h}$, cortisol and glucose levels of the shocked group remained elevated compared to controls; only for glucose, there was a significant difference between shocked and handled-only fish. Lactate levels $(H(6, N=61)=25.02, P<0.01)$ remained constant in both groups $1 \mathrm{~h}$ after treatment before decreasing, significantly for the shocked group, at $6 \mathrm{~h}$. Levels in both groups are back to control after $24 \mathrm{~h}$.
Ionoregulation-related parameters

The plasma levels of $\mathrm{Na}^{+}$and $\mathrm{Cl}^{-}$are shown in Table 1 . No significant differences in both plasma ionic concentrations were found $\left(\mathrm{Na}^{+}: H(6, N=45)=13.65\right.$, $\left.P=0.034 ; \mathrm{Cl}^{-}, P=0.91\right)$. No differences in $\mathrm{Na}^{+} / \mathrm{K}^{+}$ATPase activity were found among the groups tested $(H(6, N=58)=15.51, P=0.017)$. Plasma osmolality $(H(6, N=68)=35.80, P<0.01)$ significantly decreased from $1 \mathrm{~h}$ post stimulus in the shocked group, and recovery was not observed after $24 \mathrm{~h}$. In the handled group, a significant decrease was observed only after $6 \mathrm{~h}$, and full recovery was seen after $24 \mathrm{~h}$.

Mucus cells and chloride cells migration

Mucus cells in the control group are observed between the lamella in the filamental epithelium, in the same region where chloride cells are found (Roques et al. 2010). In all the groups, regardless of the treatment and time point, no difference in mucus cell frequency was found compared to the controls. No migration of the chloride cells was observed during the experiment.

\section{Discussion}

\section{Activity}

The fish that received the electric shock significantly decreased their general swimming activity for at least $3 \mathrm{~h}$. Fish only handled showed decreased activity (compared to controls) for $2 \mathrm{~h}$; fish that received an electroshock showed decreased activity for up to $4 \mathrm{~h}$, when compared to their controls. This difference between the two treatments indicates that the combination of handling and the electric shock has a stronger effect than the handling procedure alone. The response differed from that observed in Nile tilapia subjected to fin clip. In the latter study, the activity was enhanced after the fin clip for at least $6 \mathrm{~h}$ (Roques et al. 2010). This may be related to the different type of stimuli used. For the fin clip, the harmful stimulus was accompanied by tissue damage. The clip was speculated to result in a strong adrenergic response, which will affect both behavior and branchial mucus cell release shortly following the stimulus in Nile tilapia (Roques et al. 2010). The caudal fin is an easy target and therefore often subjected to attacks, both in the 
wild and in the husbandry conditions, resulting in conditions comparable to the fin clip procedure. In such case, the animal may have the tendency to flee from the place it was hurt (Wendelaar Bonga 1997). This would explain the enhanced activity after receiving the clip, a stimulus with physical damage. The electric shock is a novel experience for the fish and did not provoke physical damage under the conditions applied. The apparent quietness in the first hours following the electroshock in Mozambique tilapia likely reflects the different nature of the stimulus compared to the fin clip, but may also be a species-specific response. The faster recovery in the handled group compared to the shocked group is an indicator that the stimulus was perceived as noxious, potentially painful. Nevertheless, the recovery seems faster in the current study (compared with the fin clip), suggesting that the electrical stimulus was potentially perceived as less noxious than the fin clip.

\section{Chafing behavior}

Mozambique tilapia that were subjected to either an electric stimulus or only handling completely stopped to display chafing behavior for almost up to $2 \mathrm{~h}$. Fish that received the electric shock seemed to recover slower (by $15 \mathrm{~min}$ ) than the handled-only group.

Chafing has been widely observed among numerous families of teleost fish, including Cichlidae and Mozambique tilapia (Oppenheimer and Barlow 1968; Barlow and Green 1970; Wyman and Walters-Wyman 1985). It is considered as a maintenance behavior, with the primary goal to remove parasites or particles from the body surface of the fish (Galhardo et al. 2008; Wyman and Walters-Wyman 1985). In case of fish raised in captivity, with poor environmental conditions, it was speculated that chafing may reflect a redirected behavior when the natural environment is unavailable, or in response to an adverse context (Galhardo et al. 2008; Wyman and Walters-Wyman 1985). Galhardo et al. (2008) observed that chafing is more important in Mozambique tilapia when substrate is absent in comparison with substrate-enriched tanks. Furthermore, she speculated that this behavior might serve as a coping mechanism, revealing conflict, frustration, or disturbance due to the presence in an unfavorable environment. In the present study, we can stipulate that fish in the control condition can be considered in a state of frustration as she described above, due to the relatively poor enrichment of the environment (standard laboratory conditions: glass aquaria, half covered, without substrate). When the electric shock is applied to the fish, they may be emotionally affected and therefore stop to display such type of stereotypical behavior as a result of a disturbance. Individuals receiving the noxious stimulus (electric shock) can be seen as more affected in comparison with the handled-only fish, since they start to display this behavior later. The performance of such behavior may apparently be overruled by a noxious, potentially painful stimulus.

The changes in both chafing and general swimming (crossing) activity indicate that there is a differential response between the shocked group and the handledonly group, the latter one recovering faster. These behavioral pattern changes are clear indications that the electric shock is perceived as potentially painful. This underlines the importance to monitor behavioral parameters in welfare and pain-related studies in teleosts (Sneddon 2003; Sneddon et al. 2003a, b; Roques et al. 2010).

\section{Stress and plasma analyses}

The plasma cortisol level increased in response to handling only and the electric shock, but did not differ between the two conditions. Basal plasma cortisol levels in our fish were in the range considered normal for non-stressed fish, that is, 33.9 (29.5) nM (Wendelaar Bonga 1997). The handling and shocked groups increased significantly cortisol levels $1 \mathrm{~h}$ post treatment both for the electric-shock and for the handling controls and remained significantly elevated at $6 \mathrm{~h}$ post treatment compared to the control. Increases up to $165.6 \mathrm{nM}(60 \mathrm{ng} / \mathrm{ml})$ are generally referred to as a mild response, while rapid increases above $276 \mathrm{nM}$ $(100 \mathrm{ng} / \mathrm{ml})$ are generally considered to reflect a severe stress response (Wendelaar Bonga 1997). When fish experience chronic stress, plasma cortisol level should remain elevated compared to controls (Wendelaar Bonga 1997), but in our fish cortisol levels returned to control values by $24 \mathrm{~h}$, which indicates that the fish recovered from the procedures. In the same species as used here, $2 \mathrm{~h}$ of net confinement was reported to induce cortisol to rise from 5-8 to $440 \mathrm{nM}$ (Nolan et al. 1999). Plasma cortisol in Nile tilapia receiving tailfin clip or submitted to handling stress only rose significantly after $6 \mathrm{~h}$ (334.6 nM (292.2) and $256.4 \mathrm{nM}$ 
(139.9), respectively) (Roques et al. 2010). No differences were observed between the two treatments, as in current study. Such results indicate that the electroshock given to the fin represented a relatively mild stress when evaluated by cortisol response in comparison with other stimuli. This plasma parameter showed a different pattern in comparison with the fin clip study, stressing once more the difference between the two types of stimulus, targeting the same body part. Furthermore, as no differences were observed between the shocked groups and their related handling stress groups, plasma cortisol seems not suitable to assess the actual effect of such mild noxious stimulus in terms of potential pain indicator.

Plasma glucose and lactate levels followed the changes observed in cortisol levels, with significantly increased glucose levels compared to the controls after $1 \mathrm{~h}$ for both groups. Plasma glucose of the shocked group remain significantly higher compared to the control and handled groups at $6 \mathrm{~h}$. Lactate levels had slightly decreased after $6 \mathrm{~h}$, and no difference between the two groups was observed. It appears that both treatments affect the fish; cortisol has a stimulatory effect on glycaemia that lasted longer in the case of the electric shock. This long-lasting effect was not observed for the fin clip (Roques et al. 2010). For this parameter, an electroshock seems to have a stronger effect. This could be due to the nature of the stimulus, the clip inducing acute strong adrenergic response due to the tissue damage, while the electroshocks induce a longer-lasting endocrine and behavioral response, probably due to its unusual (unpredictable and novel) nature. A decrease in plasma lactate can be interpreted as use of lactate as metabolic substrate for gluconeogenesis to cope with the adverse situation. The endocrine mediators involved in this process have not been investigated in this study. Polakof and Soengas (2008) demonstrated in rainbow trout injected either intraperitoneally (IP) or intracerebroventricularly (ICV) with 1-(+)-lactate that lactate metabolism was apparently involved in glucose homeostasis through changes in plasma glucose levels and glucose production in liver. They suggested that lactate was probably being converted into glucose by the liver, resulting in higher plasma levels of glucose, and, as a result, an increase in glucose availability.

Plasma concentrations of $\mathrm{Na}^{+}$and $\mathrm{Cl}^{-}$, the two determining components of plasma osmolality, did not significantly change after the shock and handling.
There was a tendency for the level of these two ions (independently) to decrease after both treatments over the time. Indeed, plasma osmolality (determined mostly by the levels of these two ions) did decrease significantly for both groups, with an apparent stronger effect for the shocked group. These observations support the relative mildness of the stimuli applied and indicate a mild loss of control over permeability to water and ions, as is often seen in stressed fish, due to catecholamine-induced epithelial lifting and dysfunction of the gills (Wendelaar Bonga 1997). This mild loss of ions is counteracted at the level of the gills by a slight increase in $\mathrm{Na}^{+} / \mathrm{K}^{+}$-ATPase activity, observed for both stimuli, after $6 \mathrm{~h}$.

Unlike in a previous experiment (Roques et al. 2010) where an increased mucus secretion was observed $1 \mathrm{~h}$ post stimulus, mucus secretion was not enhanced in the present experiment. This is additional evidence for a differential response of the fish toward two different stimuli: the fin clip induced a stronger acute adrenergic response associated with the tissue damage than the response to an electric shock.

\section{General conclusions}

A fin clip and an electric shock elicit differential responses, qualitatively and quantitatively.

While the fin clip elicited a strong acute adrenergic response, especially at the level of the gills (mucus secretion, chloride cells migration), accompanied by an enhanced swimming activity and a preference for the dark compartment, this was not observed in the current study. The stereotypical chafing behavior provides a reliable marker for discomfort. Physiological parameters were mildly affected mainly from $6 \mathrm{~h}$ post stimulus (glucose, lactate, osmolality), with only glucose levels significantly different compared to handled controls.

Behavior showed an opposite pattern, the animals being less active following the stimulus, with a slower recovery in shocked fish compared to handled-only fish. We ascribe these differences to the different nature of the stimuli; the tissue-damaging fin clip induces a strong and acute adrenergic response of short duration, and the electric shock, a novel stimulus, elicited a longer-lasting reaction.

Our results show that exposure of Mozambique tilapia to a mild electric shock impairs its welfare. This is relevant as the European Food Safety Authority 
(EFSA) recognizes that farmed fish at slaughter run the risk to be exposed to currents too low to provoke immediate loss of consciousness. Our study supports the EFSA recommendations on electronstunning conditions for fish.

Acknowledgments We would like to thank Henk Gunnink (Livestock Research, Wageningen UR) for providing the video recording equipment.

Open Access This article is distributed under the terms of the Creative Commons Attribution Noncommercial License which permits any noncommercial use, distribution, and reproduction in any medium, provided the original author(s) and source are credited.

\section{References}

Apkarian AV, Bushnell MC, Treede R-D, Zubieta J-K (2005) Human brain mechanisms of pain perception and regulation in health and disease. Eur J Pain 9:463-484

Barlow GW, Green RF (1970) The problems of appeasement and of sexual roles in the courtship behaviour of the blackchin mouthbreeder, Tilapia melanotheron (Pisces: Cichlidae). Behaviour 36:84-115

Bermond B (1997) The myth of animal suffering. In: Dol M, Kasamoentalib S, Lijmbach S, Rivas E, van den Bos R (eds) Animal consciousness and animal ethics: perspectives from the Netherlands. Van Gorcum, Assen, pp 125-143

Braithwaite VA, Huntingford FA (2004) Fish and welfare: do fish have the capacity for pain perception and suffering? Anim Welf 13:S87-S92

Chandroo KP, Duncan IJH, Moccia RD (2004) Can fish suffer? Perspectives on sentience, pain, fear and stress. Appl Anim Behav Sci 86:225-250

Chervova LS (1997) Pain sensitivity and behaviour of fishes. J Ichthyo 37:106-111

Dang ZC, Lock RAC, Flik G, Wendelaar Bonga SE (2000) $\mathrm{Na}^{+} /$ $\mathrm{K}^{+}$-ATPase immunoreactivity in branchial chloride cells of Oreochromis mossambicus exposed to copper. J Exp Biol 203:379-387

Galhardo L, Oliveira RF (2009) Psychological stress and welfare in fish. ARBS Annu Rev Biomed Sci 11:1-20

Galhardo L, Correia J, Oliveira RF (2008) The effect of substrate availability on behavioural and physiological indicators of welfare in the African cichlid (Oreochromis mossambicus). Anim Welf 17:239-254

IASP (International Association for the Study of Pain) (1979) Pain terms: a list with definitions and notes on usage. Recommended by the IASP Subcommittee on Taxonomy. Pain 6:249-252

Lynn B (1994) The fibre composition of cutaneous nerves and the classification and response properties of cutaneous afferents, with particular reference to nociception. Pain Rev 1:172-183
Maximino C, Marques de Brito T, Dias CA, Gouveia A Jr, Morato S (2010) Scototaxis as anxiety-like behavior in fish. Nat Protoc 5:209-216

Metz JR, van den Burg EH, Wendelaar Bonga SE, Flik G (2003) Regulation of branchial $\mathrm{Na}^{+} / \mathrm{K}^{+}$-ATPase in common carp Cyprinus carpio acclimated to different temperatures. J Exp Biol 206:2273-2280

Metz JR, Geven EJW, van den Burg EH, Flik G (2005) ACTH, $\alpha-\mathrm{MSH}$, and control of cortisol release: cloning, sequencing, and functional expression of the melanocortin-2 and melanocortin-5 receptor in Cyprinus carpio. Am J Physiol 289:R814-R826

Nilsson J, Kristiansen TS, Fosseidengen JE, Fernö A, Van den Bos R (2002) Learning in cod (Gadus morhua): long trace interval retention. Anim Cogn 11:215-222

Nolan DT, Op't Veld RLJM, Balm PHM, Wendelaar Bonga SE (1999) Ambient salinity modulates the response of the tilapia, Oreochromis mossambicus (Peters), to net confinement. Aquaculture 177:297-309

Nordgreen J (2009) Nociception and pain in teleost fish. PhD thesis, Norwegian School of Veterinary Science, Norway

Oppenheimer JR, Barlow GW (1968) Dynamics of parental behavior in the black-chinned mouthbreeder. Tilapia melanotheron (Pisces: Cichlidae). Tierpsycho 25:889-914

Polakof S, Soengas JL (2008) Involvement of lactate in glucose metabolism and glucosensing function in selected tissues of rainbow. J Exp Biol 211:1075-1086

Portavella M, Vargas JP, Torres B, Salas C (2002) The effects of telencephalic pallial lesions on spatial, temporal, and emotional learning in goldfish. Brain Res Bull 57:397-399

Pottinger TG, Pickering AD (1997) Genetic basis to the stress response: selective breeding for stress-tolerant fish. In: Iwama GK, Pickering AD, Sumpter JP, Schreck CB (eds) Fish stress and health in aquaculture. Cambridge University Press, Cambridge, pp 171-193

Roques JAC, Abbink W, Geurds F, van de Vis H, Flik G (2010) Tailfin clipping, a painful procedure: studies on Nile tilapia and common carp. Physiol Behav 101:533-540

Rose JD (2002) The neurobehavioral nature of fishes and the question of awareness and pain. Rev Fish Sci 10:1-38

Schram E, Roques JAC, Abbink W, Spanings T, De Vries P, Bierman S, Van de Vis H, Flik G (2010) The impact of elevated water ammonia concentration on physiology, growth and feed intake of African catfish (Clarias gariepinus). Aquaculture 306:108-115

Sneddon LU (2002) Anatomical and electrophysiological analysis of the trigeminal nerve in a teleost fish, Oncorhynchus mykiss. Neurosci Lett 319:167-171

Sneddon LU (2003) The evidence for pain in fish: the use of morphine as an analgesic. Appl Anim Behav Sci 83: 153-162

Sneddon LU, Braithwaite VA, Gentle MJ (2003a) Novel object test: examining pain and fear in the rainbow trout. J Pain 4:431-440

Sneddon LU, Braithwaite VA, Gentle MJ (2003b) Do fish have nociceptors? Evidence for the evolution of a vertebrate sensory system. Proc R Soc 270:1115-1121

Van de Vis H, Kestin SC, Robb D, Oehlenschläger J, Lambooi B, Münkner W, Kuhlmann W, Kloosterboer K, Tejada M, Huidobro A, Otterå H, Roth B, Sørensen NK, Aske L, 
Byrne H, Nesvadba P (2003) Is humane slaughter of fish possible for industry? Aquac Res 34:211-220

Van der Heijden AJH, Verbost PM, Eygensteyn J, Li J, Wendelaar Bonga SE, Flik G (1997) Mitochondria-rich cells in gills of tilapia (Oreochromis mossambicus) adapted to freshwater water or seawater: quantification by confocal laser scanning microscopy. J Exp Biol 200:55-64
Wendelaar Bonga SE (1997) The stress response in fish. Physiol Rev 77:591-625

Wyman RL, Walters-Wyman MF (1985) Chafing in fishes: occurrence, ontogeny, function and evolution. Environ Biol Fish 12:281-289 